\title{
Resolution-fatigue syndrome: the contribution of health policy and systems research to the SDGs
}

\author{
Viroj Tangcharoensathien ${ }^{1 *}$, Lucy Gilson ${ }^{2}$ and Abdul Ghaffar ${ }^{3}$ \\ ${ }^{1}$ Viroj Tangcharoensathien, International Health Policy Program, Ministry of Public Health, Thailand \\ ${ }^{2}$ Lucy Gilson, University of Cape Town, South Africa \\ ${ }^{3}$ Abdul Ghaffar, Alliance on Health Policy and Systems Research, WHO Geneva, Switzerland
}

The Global Symposium on Health Systems Research is a landmark biannual conference where health policy and systems research (HPSR) communities, including policy makers and other stakeholders, review progresses on research and the capacities to inform and influence health policies and systems. The $5^{\text {th }}$ Global Symposium was held last year in Liverpool, which specifically considered the action and research needed to advance the health related sustainable development goals (SDG).

SDGs offer opportunities as well as challenges for HPSR to play a greater role in informing multisectoral actions for health [1] opportunities in terms of its multi-disciplinary approaches and challenges in term of the increased complexity of multisectoral actions in addressing social, environmental and commercial determinants outside the health sector's primary remits.

Despite numerous and repeated UN General Assembly Resolutions and High Level Political Declarations related to health; notably Resolution A/RES/72/139 calling for a UN high-level meeting on Universal Health Coverage (UHC) in 2019, A/RES/72/138 which proclaims 12 December as International UHC Day, Tuberculosis (A/ RES/73/3), NCD (A/RES/73/2), HIV/AIDS (A/RES/65/277), Road Safety (A/RES/70/260); there is insufficient progress in low- and middle-income countries (LMIC). This phenomenon, "ResolutionFatigue Syndrome", is underpinned by several root causes.

Key root causes include thelack of political and financial commitment to health which is reflected by limited access by poor households [2], and high levels of out of pocket spending on health leading to catastrophic health expenditures even by non-poor households [3]. The "know-do" gap [4] is founded on the lack of implementation capacity, weak and inequitable distribution of primary healthcare, high levels of absenteeism among health personnel [5], shortage of essential medical products, or high prevalence of substandard and falsified medicines [6]. Monitoring and Evaluation capacity to measure progress and public reporting are also inadequate to hold government accountable.

The solutions to the root causes of "Resolution-Fatigue Syndrome" cannot be solved by another UN General Assembly or World Health Assembly resolution. Controlling use of tobacco, alcohol and ensuring road safety require effective governance of multi-sectoral actions for health. The proposed strategies by Rasanathan, et al. [7] - in particular, managing relationships and conflicts between stakeholders and providing incentives for institutions and individuals to collaboraterequire further adaptation to suit the socio-political contexts in different LMICs.
Lack of implementation capacities is a key challenge. For example, there are 1 and 12 full time equivalent staff working in tobacco control in Timor-Leste and Indonesia, each of which spent US\$ 180 and US\$ 0.56 million, respectively, on tobacco control. Yet both countries have the highest global smoking prevalence rates, at $43 \%$ and $39 \%$ in 2016 [8]. In contrast, with an adult cigarette smoking $13 \%$ in Canada; the government invested on 89 full time equivalent staffs and spent US\$ 34 million in 2016 for tobacco control.

Table 1 shows the number of full time equivalent contributed to and government spending on tobacco control; among the top ten countries with the highest prevalence of adult smoking between 2000 and 2016. Clearly these capacities cannot make a change in stabilizing and reversing adult smoking prevalence.

While government action is weak, the "deep pocket" industries are strong. In the US, tobacco companies' spending on cigarette advertising and promotion increased from US\$ 8.03 billion in 2014 to US $\$ 8.24$ billion in 2015, mainly as a result of the price discounts given to wholesalers to reduce cigarette prices and so, boost sales volume [9].

The unethical practices of tobacco company lawyers in concealing evidence of tobacco harm to the public and their aggressive and threatening litigation have prevented many governments from taking tough measures [10]. A few young and inexperienced government lawyers cannot fight back thousands of lawyers in international law firms hired by the tobacco and alcohol industry.

Even in countries having relatively higher capacities such as in Thailand and Australia, industry has filed law suits against these governments for increasing the space given to health warnings to $85 \%$ of front and back package areas (Thailand) and plain packaging (Australia).

The few drops of current government effort cannot address the sea of challenges. Yet one sign of hope lies in the HPSR community, which seeks to produce and provide local knowledge to country leadership to counter the arguments and influence of those who work against

${ }^{\star}$ Correspondence to: Viroj Tangcharoensathien, International Health Policy Program, Ministry of Public Health, Thailand, E-mail: viroj@ihpp.thaigov.net

Key words: health systems and policy research, evidence informed policy, resolution-fatigue syndrome, implementation capacities, health related SDG

Received: July 17, 2019; Accepted: July 25, 2019; Published: July 29, 2019 
Table 1. Number of full-time equivalent staff and government expenditure for tobacco control: top ten highest adult smoking prevalence, $2000-2016$

\begin{tabular}{|c|c|c|c|c|c|c|c|c|c|c|}
\hline Country Name & $\mathbf{2 0 0 0}$ & $\mathbf{2 0 0 5}$ & $\mathbf{2 0 1 0}$ & $\mathbf{2 0 1 1}$ & $\mathbf{2 0 1 2}$ & $\mathbf{2 0 1 3}$ & $\mathbf{2 0 1 4}$ & $\mathbf{2 0 1 5}$ & $\begin{array}{c}\mathbf{2 0 1 6} \\
\begin{array}{c}\text { Full time equivalent for } \\
\text { tobacco control }\end{array}\end{array}$ Government spending on \\
tobacco control, US\$
\end{tabular}

Source: WDI 2018, WHO 2017 MPOWER at https://bit.ly/32vQhXI

the interests of those who are socially marginalized. It is important to set HPSR priorities in response to country challenges. For example, research is needed to understand and develop improved regulatory capacities and avoid regulatory capture [11], implementation and policy research can improve government accountability mechanisms or test approaches for minimizing absenteeism.

The HPSR community can make use of the annual International UHC day, not to repeat the talk but to "walk the talk" by critical review of the progress of UHC and health-related SDG targets and by setting milestone for annual follow up with stakeholders. Implementation capacities can be boosted through embedded research with the implementing agencies on governing mechanisms, accounting for contextual factors.

HPSR capacities depend on developing a critical mass of competent researchers who conduct HPSR in recognition of real-life socio-political constraints. Such researchers understand the policy actors and power dynamics, stay at the "policy ring side" and address policy relevant questions. Further, sustaining HPSR capacities is equally as important as building them up; it requires an enabling environment and mentorship support. Globally, significant scale up of HPSR capacity is required to address the challenges to achieving the SDGs.

\section{Authorship and contributorship}

All authors framed the idea of this commentary and contributed equally in writing. VT combined all parts and presented the first draft for comments. All authors strengthened the text and approved the final draft.

\section{Acknowledgements}

We acknowledge the contributions of health policy and systems research communities in advancing the discipline which supports generating evidence and inform health policies.

\section{Funding}

There is no funding support to this work.

\section{Competing interests}

We declare no competing interests.

\section{References}

1. Peters DH (2018) Health policy and systems research: the future of the field. Heal Res policy Syst 16: 84

2. Hogan DR, Stevens GA, Hosseinpoor AR, Boerma T (2018) Monitoring universal health coverage within the Sustainable Development Goals: development and baseline data for an index of essential health services. Lancet Glob Heal 6: e152-68.

3. Wagstaff A, Flores G, Smitz M-F, Hsu J, Chepynoga K, et al. (2018) Progress on impoverishing health spending in 122 countries: a retrospective observational study. Lancet Glob Heal.

4. Mohanan M, Vera-Hernandez M, Das V, Giardili S, Goldhaber-Fiebert JD, et al. (2018) The know-do gap in quality of health care for childhood diarrhea and pneumonia in rural India. JAMA Pediatr 169: 349-357. [Crossref]

5. Kisakye AN, Tweheyo R, Ssengooba F, Pariyo GW, Rutebemberwa E, et al. (2016) Regulatory mechanisms for absenteeism in the health sector: a systematic review of strategies and their implementation. J Healthc Leadersh 8: 81-94.

6. Ozawa S, Evans DR, Bessias S, Haynie DG, Yemeke TT, et al. (2018) Prevalence and estimated economic burden of substandard and falsified medicines in low- and middle-income countries: A systematic review and meta-analysis. JAMA Netw Open 1: e181662.

7. Rasanathan K, Atkins V, Mwansambo C, Soucat A, Bennett S (2018) Governing multisectoral action for health in low-income and middle-income countries: an agenda for the way forward. BMJ Glob Heal P: 3.

8. World Health Organization (2017) Tobacco control country profiles.

9. Federal Trade Commission. FTC Releases Reports on 2015 Cigarette and Smokeless Tobacco Sales and Marketing Expenditures.

10. Guardino SD, Daynard RA (2007) Tobacco industry lawyers as "disease vectors". Tob Control 16: 224-228. [Crossref]

11. Kanchanachitra C, Tangcharoensathien V, Patcharanarumol W, Posayanonda T (2018) Multisectoral governance for health: challenges in implementing a total ban on chrysotile asbestos in Thailand. BMJ Glob Heal p: 3.

Copyright: (C2019 Tangcharoensathien V. This is an open-access article distributed under the terms of the Creative Commons Attribution License, which permits unrestricted use, distribution, and reproduction in any medium, provided the original author and source are credited. 